\title{
N ise da Silveira: imagens do inconsciente entre psicologia, arte e política
}

J OÃ O A. FRAYZE-PER EIRA

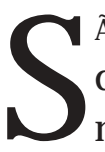
ão tAN tos os aspectos que poderiam ser destacados na longa vida de $\mathrm{N}$ ise da Silveira que a tarefa de escrever sobre ela no espaço de um artigo se tornaria muito complexa. 0 encontro com a Psicologia de Jung, aprofundado pela análise pessoal com M arie-L ouise von Franz e pela freqüentação do I nstituto C. G. J ung, em Zurich; as relações com o pensamento de Artaud, com a poética de Bachelard e com idéias de Spinoza; a prática no Setor de Terapêutica O cupacional no antigo Centro Psiquiátrico $\mathrm{N}$ acional, Engenho de D entro (R io de Janeiro.), lugar de origem do M useu de I magens do Inconsciente, e posteriormente na Casa das Palmeiras, instituição pioneira fundada por ela para o tratamento dos pacientes em regime de portas abertas; o respeito pelos animais, especialmente cães e gatos, eleitos por ela "co-terapeutas" ; a paixão pela arte e o diálogo com a crítica de arte de melhor extração no Brasil, relações que Ihe deram suporte para deslocar a problemática da loucura, em geral, e da esquizofrenia, em particular, do campo da psicopatologia médica para o campo da cultura, entre outros aspectos, são os que mereceriam a particular atenção do interessado na vida e na obra dessa figura que se tornou lendária na cultura brasileira, a doutora N ise da Silveira*. N o entanto, considerando os limites deste artigo, decidi partir dos meus próprios contatos com a doutora, breves mas significativos, iniciados por correspondência no final dos anos de 1970, quando solicitei a ela a separata de um trabalho publicado numa revista inexistente nas bibliotecas paulistanas. A leitura desse artigo, Comentário sobre D yonisos, surpreendeu-me imediatamente. Analisando a figura de $D$ yonisos no contexto da obra de Leonardo da Vinci, N ise da Silveira (1973) desvenda a figura de João Baptista - um antiD yonisos. Tempos depois, em 1981, um encontro feliz e inesperado veio a ocorrer na exposição "Arte Incomum" da 16ạ Bienal Internacional de São PauIo, na qual eu trabalhei como pesquisador e a doutora $\mathrm{N}$ ise lançou o livro I magens do inconsciente. Em seguida, a convite dela, fiz várias visitas ao M useu de I magens do Inconsciente, conheci seus artistas e acabei escrevendo a respeito (Frayze-Pereira, 1995; 1999).

* As biografias escritas por Walter M elo (2001) e Ferreira G ullar (1996) são exemplares, nesse sentido. 
A crermos em Eurípedes, os mitos dionisíacos apresentam certas características que indicam a negação da esfera privada e da esfera pública, do oi kos e da polis. Inversamente à religião oficial que se prende ao ideal da sophrosyne, ao controle harmônico do indivíduo dentro de certas normas, o dionisismo aparece como uma libertação. B asta lembrar que nas Bacantes, o cosmos retorna ao caos a fim de que tudo possa renascer. O ra, no contato inicial com a obra de $\mathrm{N}$ ise da Silveira o meu próprio trabalho de pesquisa reordenou-se, transitando entre a estética da recepção e a psicanálise da criação artística, composição esta que dura até hoje. $\mathrm{N}$ esse sentido, falar da doutora $\mathrm{N}$ ise é lembrar a potência de sua obra. É registrar a força dessa mulher tímida, inteligente e obstinada, conforme a definiu G raciliano Ramos que a conheceu no cárcere junto com O Iga Prestes. N ão bastasse ser mulher e nordestina, médica e psiquiatra, foi também uma antipsiquiatra precoce, com idéias socialistas em pleno Estado N ovo. E foi dessa configuração muito singular que certamente resultou a obra que a tornou conhecida no Brasil e no exterior: o M useu de I magens do Inconsciente. Como definir esse M useu?

Costuma-se dizer que o M useu de I magens do Inconsciente se constituiu desde o princípio como um núcleo de pesquisa da esquizofrenia - núcleo liderado por sua criadora que, em última análise, utilizou a expressão plástica como um meio de acesso à interioridade dos esquizofrênicos e levou ao conhecimento do grande público as obras de seus pacientes. Essa caracterização é realista. N o entanto, é bastante acanhada se quisermos apreender a complexidade simbólica do campo que esse museu inaugura, complexidade que surge se tomadas em consideração as milhares de imagens que aí foram elaboradas, desde a sua fundação, em 1952. N essa direção, a trilogia do cineasta Leon H irszman intitulada I magens do inconscientefaz uma apresentação sintética e muito sensível desse campo de sentidos que abre a passagem entre o hospício e o mundo das imagens, campo que articula psicologia, arte e política numa única trama cultural.

Com efeito, o primeiro filme, Em busca do espaço quotidiano, é centrado em Fernando Diniz (1918-1999), um dos pacientes que se tornou artista nos ateliês do M useu, cuja obra é focada pelo cineasta à luz de uma problemática que passa pelo conflito social de classes, pelo preconceito cultural e pela humilhação existencial. É o filme que aborda a instauração do M useu e tematiza a sua significação mais radical: a significação sociopolítica. 0 segundo filme, $N$ o réno das mães, situa A delina Gomes (1916-1984) no campo das figuras míticas, criando uma atmosfera onírica com a técnica de obscurecimento das imagens em close e permitindo uma aproximação emocionante do público com a artista no plano do imaginário. Já o terceiro filme, $\mathrm{A}$ barca do sol, baseado na obra de $\mathrm{C}$ arlos Pertius (1916-1977), é o mais difícil da trilogia, talvez o mais aberto, certamente o mais místico, abarcando a saída do paciente/ artista para a morte logo após a figuração plástica do encontro simbólico com a consciência. Sabe-se que a barca do sol é uma imagem recorrente em diversos mitos. No livro I magens do inconsciente (1981), significativamente, é a imagem estampada na capa, como se fosse um 
emblema do que nele é tematizado. E sobre o seu advento na obra de Carlos Pertius, $N$ ise da Silveira escreveu: "A face do sol é serena e triste. Ele vai navegar na noite e lutar contra monstros que incessantemente se esforçam por impedir seu renascimento. Esta pintura está datada de 2 de dezembro de 1976. Carlos morreu a 21 de março de 1977" (p. 314). A morte da doutora, no dia 30 de outubro de 1999, deu-se após a morte de todos os pacientes-artistas que cuidou ao longo de mais de cinco décadas - uma longa e paciente espera. E como ela sempre desejou que as pessoas aprendessem a morrer, em seus últimos momentos de vida, permaneceu lúcida, "conscientemente livre", antes de, em seu "fôlego de sete gatos", mergulhar na "Substância I nfinita" (M elo, 2001, p. 149).

0 que é importante observar nessa trilogia de $\mathrm{H}$ irszman é a reflexão que realiza. Ela perfaz um círculo em cujo centro encontramos essa figura que viveu quase um século, deu sentido ao processo de filmagem e também ao que vemos nos filmes. $\mathrm{N}$ ise da Silveira é de certa maneira a grande personagem de que tratam os filmes; até certo ponto, sua co-autora. E Leon não foi o primeiro a fazer esse movimento. Antes dele Graciliano Ramos, M ario Pedrosa, Ferreira Gullar, Frederico M oraes, J orge de Lima, Sergio M illiet, Carlos D rumond e muitos outros o fizeram. É como se para falar do M useu e de suas atividades, para falar da questão arte-loucura, de suas implicações estéticas e culturais, não pudéssemos prescindir de sua pessoa. $E$, no entanto, os filmes que compõem essa trilogia não são biográficos, nem experimentais; não são ficções, mas também não são documentários. São esteticamente incomuns. Vendo-os tem-se a impressão de que a questão abordada é a questão da viagem, uma viagem épica que parte em busca do espaço cotidiano, navega em direção ao sol, passando pelo reino das mães. E, como nas epopéias, são inúmeras as alienações vencidas para, ao final das provas, os heróis reconciliarem-se consigo mesmos, ainda que no mundo das imagens. E do espaço cotidiano ao mítico, o espectador é embalado pelo sedutor discurso fílmico, mas também pela dramática voz que narra. Essa voz éa de Vanda L acerda, atriz e locutora da era do rádio no Rio de J aneiro. M as poderia ser a de $\mathrm{N}$ ise da Silveira, porque é como a encarnação da figura do $\mathrm{N}$ arrador, tematizada por Walter Benjamim, que $\mathrm{N}$ ise se apresenta aos seus leitores. É uma narrativa que tem o poder de encantar o leitor porque busca reencantar o mundo. Q uer dizer, a narrativa articuladora desses filmes não se prende à racionalidade cientificista despoetizadora. É uma narrativa que asso cia pensamento e emo ção numa longa e paciente espera pelo advento do sentido junto ao O utro, numa atitude que é contrária ao ritmo contemporâneo. Como ela mesma costumava dizer - "o mundo contemporâneo é impaciente. A sociedade tem pavor de resultados a longo prazo". A narrativa poética de $\mathrm{N}$ ise da Silveira tem, assim, a densidade de uma sabedoria que se apóia na memória, capacidade épica por excelência, ainda segundo Walter Benjamim (1983, p. 66) que escreveu: "somente uma memória abrangente permite à poesia épica apropriar-se do curso das coisas, por um lado, e resignar-se, por outro, com o desaparecimento dessas coisas, com o poder da morte". 
O bras Acervo M useu de I magens do Inconsciente/ RJ

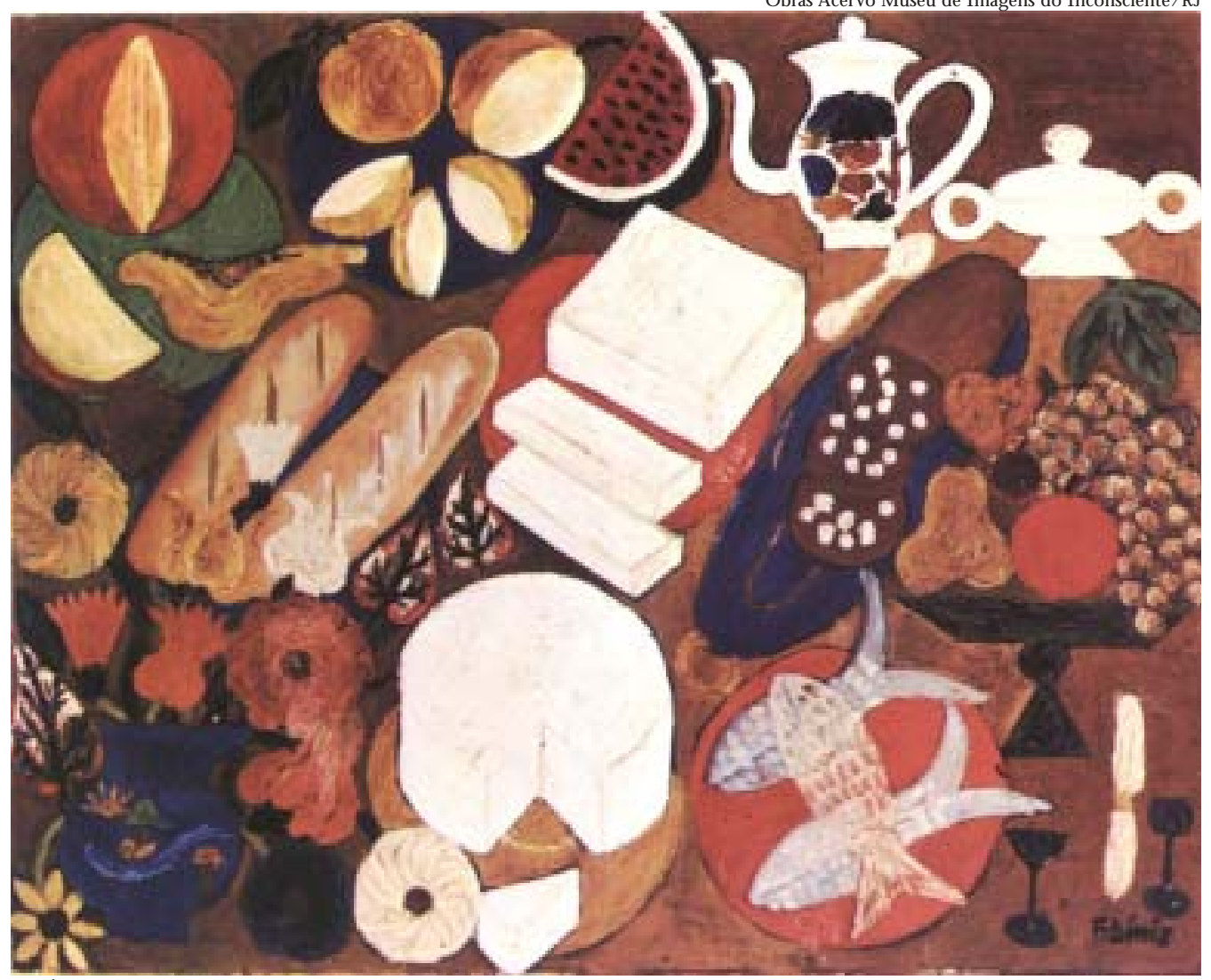

Óleo sobre tela, 83,0 x 67,0 cm, 1954, por Fernando Diniz.

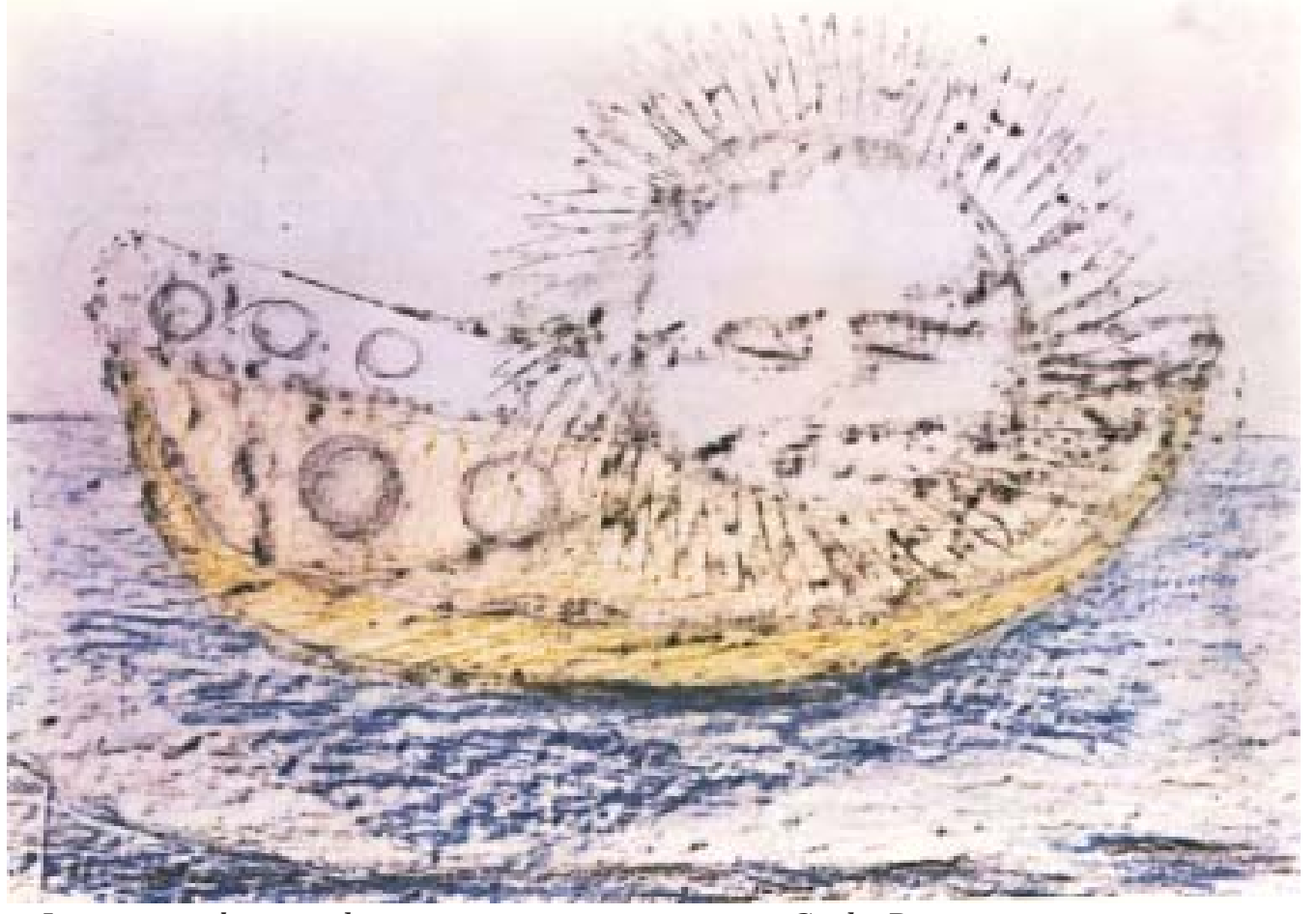

Lápiscera sobre cartolina, 43,0 x 33,0 cm, 1976, por Carlos Pertius. 
É preciso lembrar que a perspectiva teórica fundante da proposta do M useu de I magens do Inconsciente vem da Psicologia Analítica de Jung. M as não só. Ela também tem raízes em obras de outros autores, filósofos e artistas, em especial na poética de Artaud, o qual $\mathrm{N}$ ise da Silveira considerou "um mestre". Referindo-se às palavras do poeta - a propósito da arte de Victor Brauner - "o ser tem estados inumeráveis e cada vez mais perigosos" - ela escreveu:

pareceu-me que Artaud referia-se a certos acontecimentos terríveis que podem ocorrer na profundeza da psique, avassalando o ser inteiro. D escarriIhamentos da direção lógica do pensamento; desmembramentos e metamorfoses do corpo; perda dos limites da própria personalidade; estreitamentos angustiantes ou ampliações espantosas do espaço; caos; vazio; e muitas mais condições subjetivamente vividas que a pintura dos internados de E ngenho de D entro tornavam visíveis (1986, p. 5).

Tal pintura revelava, para a doutora N ise, já em 1946, imagens espontâneas de pessoas que vivem estados perigosos do ser, e o trabalho do M useu consistiu em penetrar regiões misteriosas que ficam do outro lado do chamado mundo real, contrariando o modelo médico adotado pela Psiquiatria vigente, oferecendo matéria para a crítica às voltas com a problemática da arte no segundo pósguerra. Q ual era essa problemática? É a própria arte contemporânea que nasce nessa época conturbada e a crítica, a teoria e a história da arte se deparavam com a questão desse nascimento. $M$ as que sentido teria nesse momento as manifestações plásticas dos psiquiatrizados?

$\mathrm{N}$ esse período pós-guerra, desenvolve-se na Europa uma arte gestual não somente como uma reação à onda crescente de materialismo, mas contra a arte formalista, hegemônica na época; contra a criação plástica dominada pela estética cubista e suas derivações, em particular pela tendência neo-construtivista oriunda diretamente da Bauhaus. Ao formalismo, os artistas responderam com uma arte dita "informal" cujas numerosas variações se opõem a todo princípio geométrico, ao intelectualismo vazio e ao superficialismo estético. O u seja, o conjunto da chamada "arte informal" é um fenômeno complexo, pluridimensional. $E$, no entanto, há um denominador comum a todos os artistas que se engajaram nesta corrente poética: a vontade de romper com uma tendência que lhes parecia opressora, autoritária, esterilizante. À geometria rígida, el es opunham as formas irregulares, à composição refletida, a improvisação e o acidente, à determinação, 0 indeterminado. Pronunciando-se a favor de toda manifestação livre da sensibilidade, dos instintos, da energia vital, os artistas e críticos afiliados a eles denunciam a arte que era mediada por conceitos. Essa arte nova, contemporânea, propunha um contato direto com o espectador seja no nível das sensações, seja no nível das emoções. 0 gesto espontâneo é considerado a expressão do ser primordial, "pré-reflexivo", nos termos de M aurice M erleau-Ponty (1964) que, em seus escritos estéticos, revela ter acompanhado o nascimento dessa arte nova. 
É nesse momento da história da arte que o pintor J ean D ubuffet lança a idéia de art brut, qualificando artisticamente, e pela primeira vez do ponto de vista da crítica, as criações dos não-profissionais, inclusive os psiquiatrizados. $\mathrm{E}$ com relação às expressões plásticas dos pacientes de $N$ ise da Silveira, $M$ ário Pedrosa (1949) escreveu a favor do que denominou arte virgem, conceito largamente aparentado às idéias de Dubuffet, isto é, uma arte que não leva em conta as convenções acadêmicas estabelecidas, "quaisquer rotinas da visão naturalista e fotográfica" ou ainda as fáceis "receitas de escola" - arte que pertence a todo ser sensível "como estes que além de artistas são alienados" (p. 115). Artistas espontâneos, esses criadores virgens começam a pintar depois de adultos e "doentes". E nada, no plano da arte, permite distinguí-los dos "normais". N esse sentido, as obras de "arte virgem" são da mesma natureza fundamental das obras dos grandes artistas universais, obedecendo a idêntico processo psíquico de elaboração criadora" , isto é, "de emprestar [...] forma aos sentimentos e imagens do eu profundo" (p. 161). Como J ean D ubuffet, M ario Pedrosa valoriza nessas manifestações o caráter transgressivo da imagem com relação ao sistema das artes, considerado pelo artista francês tão opressivo e marginalizante quanto os totalitarismos que acabavam de horrorizar o mundo. E Pedrosa vai mais longe, fundamentando tais criações em registros teóricos que não são incompatíveis com a Psicologia praticada por N ise da Silveira. Contudo, se para M ario Pedrosa (I979, p. 108) não será a interpretação do drama psíquico, vivido inconscientemente pelo artista, aquilo que vai nos dizer se estamos ou não diante de uma obra de arte, para $\mathrm{N}$ ise da Silveira (1981, p. 16) são "os problemas científicos" levantados pelas obras, além da atenção necessária ao aspecto humano do fenômeno artístico que devem motivar a tarefa do pesquisador. Em outras palavras, as obras produzidas no M useu e que aí permanecem conservadas valem por sua significação expressiva e terapêutica, isto é, à medida que oferecem ao estudioso um meio de acesso ao mundo interno dos esquizofrênicos, assim como, ao paciente, um instrumento de transformação da realidade interna e externa. $\mathrm{H}$ á, no entanto, uma aceitação tácita de que as criações dos pacientes são verdadeiras obras de arte, à medida que a autêntica obra de arte é, segundo $\mathrm{N}$ ise da Silveira, uma "produção impessoal", isto é, uma expressão do inconsciente coletivo.

O ra, é porque o artista é instrumento da arte que a psicologia do artista é um tema coletivo. Ela diz respeito àquilo que o homem é enquanto artista: "homem coletivo, portador e plasmador da alma inconsciente e ativa da humanidade". Para a doutora $\mathrm{N}$ ise, é essa a tarefa do artista, tarefa que muitas vezes lhe solicita "o sacrifício de sua vida, de sua felicidade". N esse sentido, na condição de visionário, o criador é depositário de um saber misterioso que o leva a dizer 0 indizível sem que ele mesmo o saiba porque. 0 psicótico, sempre habitado por "esse mistério, encontrará um oásis no ateliê de pintura se aí tiver a liberdade de expressão que sua obra exige" (Silveira, 1981b, p. 38). Sua biografia pessoal é secundária em relação ao que "representa como ser criador" (J ung, 1985, p. 93). E 
nessa condição poderá passar o resto de sua vida respondendo à solicitação de uma obra que possui um sentido coletivo, ou melhor, que se constitui num patrimônio da humanidade cujo caráter documental possui a significação de uma reminiscência, uma expressão do humano no sentido arcaico cujo lugar legítimo, em nossa cultura, costuma ser o museu. D iante dessa problemática, surgem algumas indagações: como e onde conservar, no contexto das instituições de saúde, a vastíssima produção dos pacientes? E que fazer com os criadores cujo destino artístico dotou-os da fragilidade, como se a Arte tivesse o poder de arrebatar a maior parte de sua energia vital? O nde abrigar essas personalidades artísticas reconhecidas? Como protegê-las? C omo assegurar-Ihes neste mundo um lugar onde possa se dar a vivência da verticalidade da existência, desses movimentos de ascensão e queda, definidores da tragédia? Partindo dessas questões, M ario Pedrosa (1980, p. 10) escreveu: "D aí nasceu com eles a idéia de museu. M as que museu? U ma coleção de belos quadros pendurados à parede, com salas contíguas para serem apreciados? N ão. O s criadores de arte, os seus produtos, não podem ser dispersos. 0 museu tem de ser também uma casa que os abrigue. $M$ as que não seja uma dessas 'colônias' de doidos por aí [...]. O M useu que a doutora $\mathrm{N}$ ise batizou, com sua habitual precisão, M useu de I magens do I nconsciente, tem por isso mesmo de completar-se numa comunidade [...] da qual não se podem afastar de lá os doentes". Somente nesse lugar, vinculados os artistas e suas obras, poderá perdurar o trabalho da criação.

N o entanto, para N ise da Silveira (I981a, p. 168), o movimento através do qual as imagens brutas são elaboradas em formas dotadas de qualidades ditas artísticas "não foi jamais explicado por nenhuma psicologia". Como o artístico é fabricado pelo artista? Eis aí "um mistério" que, segundo M ario Pedrosa (1979, pp. 76 e 118), nem o artista, nem o cientista nunca chegaram a decifrar. Em outras palavras, tanto para a terapeuta como para o crítico, a atividade observada no M useu define um fazer enigmático, uma poética incomum. O riginariamente enraizado nas oficinas de pintura e modelagem de um setor de Terapêutica $O$ cupacional, - M useu de I magens do Inconsciente foi projetado para ser um "museu vivo" (Silveira, 1980a, p. 29). U m lugar no qual criadores e criaturas pudessem realizar, sem que o soubessem como, o mistério da criação. U m lugar feminino destinado a uma obra, no qual a função da terapeuta se aproximaria, não do especialista interessado apenas na esquizofrenia, mas da figura do guardião atento à vitalidade da criação. O ra, é preciso lembrar que do ponto de vista psicanalítico, o trabalho de criação é análogo ao trabalho de parto, a relação criador-obra, à relação mãe-criança e a Psicologia da criação artística a uma psicologia feminina, " pois a obra criadora jorra das profundezas inconscientes, que são, na linguagem de Jung, o domínio das mães" (J ung, 1985, p. 91). Portanto, nada mais natural que a figura do terapeuta venha a assumir o lugar do guardião atento para salvaguardar o mistério da criação. E trata-se de uma transfiguração que não é de ordem retórica. Ela define uma tarefa concreta e uma posição política: impedir a 
qualquer preço que a obra se transforme em mero artefato, em simples mercadoria, que o museu ao longo do tempo adquira feições de um mausoléu, que ele se torne a sepultura da arte, testemunhando a banalização da cultura. E é nesse plano que a criação do artista incomum encontrará os seus limites: a sua so brevivência dependerá da força viva do guardião.

Com efeito, quando D ubuffet, na França, ou M ario Pedrosa e N ise da Silveira, no Brasil, introduziram pela primeira vez essas obras incomuns nos espaços

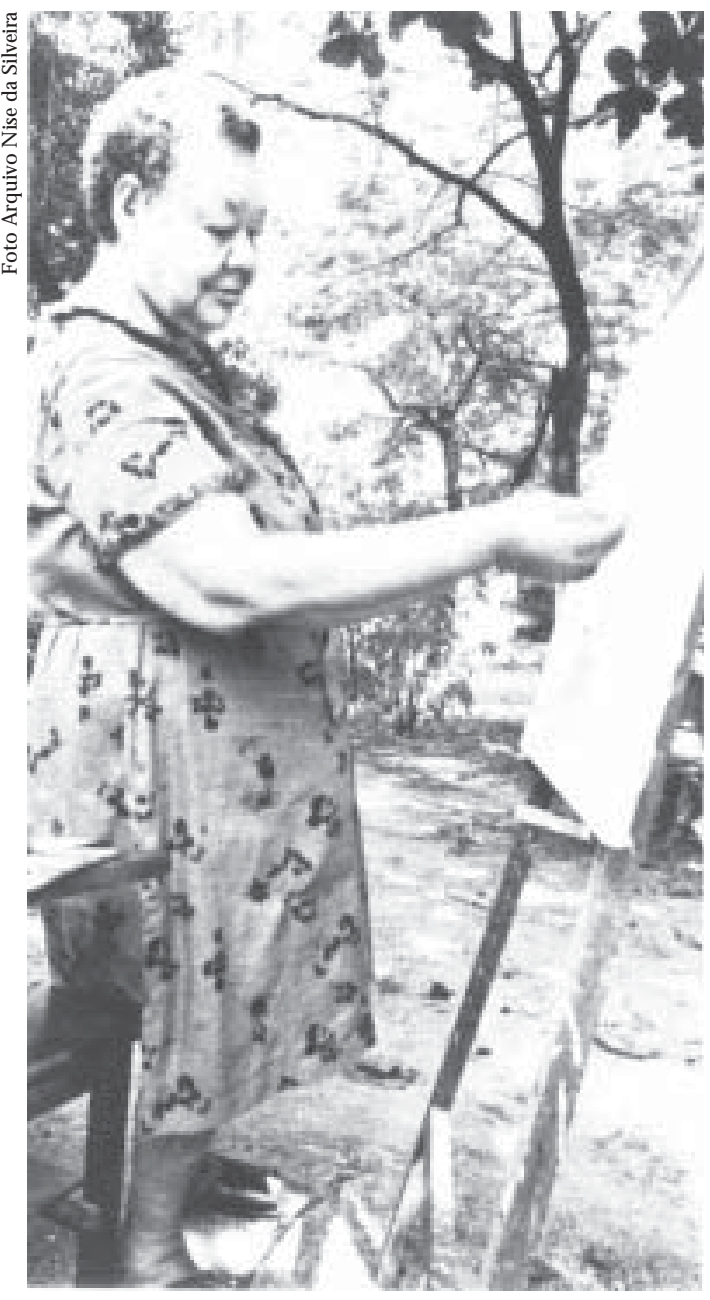

A delina Gomes destinados aos ritos de celebração da arte, como os museus e as galerias, abriu-se ao pensamento um campo no centro do qual figura a seguinte questão: o que sucederá ao artista? E muito resumidamente, pode-se dizer que na moldura de uma exposição legitimada pela cultura, a "expressão marginal" certamente ganha o selo de "obra de arte". O marginal, o louco, o psiquiatrizado torna-se artista e aos olhos do espectador "gênio". E isto significa que na contemporaneidade 0 confronto entre a loucura e a arte é o de uma luta mortal. Como dizia Foucault (1972, p. 555): "o jogo entre elas é de vida e de morte". N esse sentido, uma obra como a de Arthur Bispo do Rosário, por exemplo, ao ser posta sob os holofotes da publicidade numa exposição como a Bienal de Veneza, em 1995, sempre fica exposta aos riscos do silêncio, riscos que dependem da maneira como os espectadores e críticos vierem a se posicionar diante dessa obra, da maneira como vierem a percebê-la e a interpretá-la. O s reducionismos e as tomadas de partido estéticos ou culturais são os sinais mais óbvios de que os riscos de "condenação da loucura ao silêncio" (Foucault), mesmo no campo da arte, ainda estão presentes.

N esse sentido, comentando uma exposição de art brut que ocorreu em Washington, O tavio Paz (1987) escreveu: "tais obras não fazem pensar na clausura em que está encerrado o esquizofrênico, nem na galeria de espelhos da paranóia são ressurreições do mundo perdido de seu passado e os caminhos secretos para chegar a um outro. Q ue é esse outro mundo? D ifícil saber". São muitos os cria- 
dores que afirmam não serem eles próprios os responsáveis por suas obras, que confessam terem trabalhado sob a égide de espíritos ancestrais. E isto significa, ressalta $\mathrm{O}$ távio $\mathrm{Paz}$, que aos mortos é atribuído um papel fecundo na realização do processo criativo, cujo sentido não se esgota no fazer objetos estéticos, projeto que para o criador tem o sentido de um sagrado ofício. Sendo tais objetos um ponto de irrupção dos ancestrais numa sociedade que rompeu toda relação funcional ou simbólica com a morte - a excomunhão social de seus autores encontra aí mais uma justificativa: além da loucura, o vínculo com o além - o que Paz percebe é que essas obras não são mero conhecimento do homem interior, como também estaria de acordo $\mathrm{N}$ ise da Silveira, mas algo antigo e instintivo: "ícones, talismãs, retábulos, amuletos, efígies, simulacros, fetiches - objetos de adoração e de abominação". . N essa medida, como pensava D ubuffet, não vê muito sentido na questão arteloucura, considerada abstratamente, pois em primeiro lugar, não está claro, nem nunca estará, o que se quer dizer com essa expressão. Além do mais, a arte transcende, ou melhor, ignora a diferença entre as frágeis fronteiras da sanidade e da loucura, como ignora a diferença entre primitivos e modernos. $\mathrm{N}$ as composições desses artistas, cujo diagnóstico é freqüentemente sem esperança (esquizofrenia incurável) cumprem-se as duas exigências da arte: "ser a destruição da comunicação comum e ser a criação de uma outra comunicação". I sto é, ser a instauração de uma comunicação incomum.

N os quadros dessa posição crítica, é emblemática a obra de J acky G arnier, Tapeçaria interrompida... (Coleção Art Brut - Lausanne). I niciada em 1976, atinge vários quilômetros de comprimento, segundo um modo de associação livre, plástico e mental, que questiona radicalmente os meios convencionais de difusão: ela é invendável, irreprodutível, resistente a qualquer tipo de exposição total. Em outras palavras, Garnier subverte a rede mercantil e os modos de comunicação da arte, vinculando o fim da obra ao de sua própria vida. Como expor uma vida? - é a sua questão. Reabilitando a morte como instância de um futuro anterior, a artista liberta-se da aderência animal ao presente. $\mathrm{O}$ u seja, a morte não é o oposto da vida, mas o que a forra por dentro, um recurso imaginário, um entremundo ao qual a arte bruta nos introduz de maneira subversiva (Thévoz, 1985, 1995). O s filmes de L eon H irszmam que compõem a trilogia I magens do inconsci ente apontam para várias dessas questões com uma narrativa fílmica singular, bastante sutil. No entanto, as coisas são ainda mais complexas do que uma comunicação incomum permitiria supor.

H á que se admitir, inevitavelmente, que ao serem reconhecidos publicamente como artistas, os lou cos são apanhados pela rede da cultura e trazidos para dentro de sua órbita, ainda que excêntrica. Como diz Jean Starobinski, "ei-los incluídos após terem sido excluídos" (1984, p. xv). Entretanto, diante disso, impõe-se a nós mais uma interrogação: em que medida essa apropriação pela cultura daquilo que sempre foi a não-cultura não teria, por implicação, exorcizar a potencialidade subversiva das obras? $\mathrm{O} u$ ainda, até que ponto essa incorpora- 
ção cultural da arte de oprimidos (que transita do hospício para a galeria de arte) nada mais é do que a expressão de uma necessidade de afirmar publicamente que a opressão social não anula a força da criação?

Essas interrogações ganham força se lembrarmos as enormes dificuldades que foram encontradas por aqueles que se propuseram preservar a art brut ou introduzir a atividade poética ( não a arte-terapia ou a arte-educação) nas instituições fechadas, como os manicômios ou as prisões. Por exemplo, D ubuffet narra as dificuldades que encontrou para garantir o futuro da Coleção de Art Brut: desde 1945 a coleção migra da França para os Estados U nidos, volta à França para, finalmente, se instalar na Suíça, em 1972. No Brasil, N ise da Silveira relata os múltiplos obstáculos que, desde o início, em 1946, sua obra encontrou para se perfazer, sendo o M useu de I magens do Inconsciente seriamente hostilizado e ameaçado de extinção, em 1975. Posteriormente, em 1986, a artista carioca D enira Rozário (1986) defrontou-se com incrível resistência institucional para dar continuidade ao trabalho que iniciou com um grupo de presos nas penitenciárias Lemos de Brito e M ilton D ias M oreira (Rio de Janeiro), não Ihe sendo possível evitar a extinção. N esses dois últimos, e em muitos outros casos, é o processo instaurado na forma da expressão livre, o prazer encontrado pelos criadores numa prática com implicações poéticas de grande intensidade emocional e cognitiva, que constitui uma ameaça para o equilíbrio das instituições disciplinares, intrinsecamente voltadas para a anestesia da sensibilidade e a paralisia do pensamento, a docilização do corpo e o castigo do espírito.

No M useu de I magens do I nconsciente, de uma certa maneira, a singularidade das criações tem sido preservada. $\mathrm{E}$ isso graças sobretudo à densidade do campo simbólico inaugurado pelo trabalho de $\mathrm{N}$ ise da Silveira e as criações dos autores que apreciou, trabalho que inscreveu tais criações na singular trama cultural brasileira na mesma medida que as interpretou como universais. A leitura da obra de Adelina Gomes, por exemplo, estará para sempre ligada a essa obra que, aliás, foi por ela também constituída. Assim, jamais poderemos saber se a ninfa $D$ afne veio a introduzir-se mesmo na obra bruta de Adelina porque esta teria revivido inicialmente, em seu próprio meio familiar, o tema mítico da divindade grega, como a noção de arquétipo permite supor (Pedrosa, 1980, p. 122). De meu ponto de vista, se a leitura de uma obra é trabalho é porque é negação singular do imediato, portanto, instauração formativa do sentido e não mero desvendamento de um significado que se crê já depositado em si mesmo na obra. $\mathrm{N}$ esse sentido, no âmbito das relações complexas entre a arte e a interpretação, pode-se dizer que a obra de A delina realmente vai ao encontro de $D$ afne, porém através do trabalho firme, compassivo e delicado da doutora que, por sua vez, conduziu ambas, mulher e divindade, para o solene interior de um M useu, uma nova obra, cujo belo percurso em nossa cultura, sugere, pela força de propósitos de sua criadora, a retomada simbólica do sentido originário do mousei on, "um local privilegiado, onde o pensamento, liberto dos problemas e aflições cotidia- 
nos, poderia se dedicar às artes e às ciências. As obras de arte expostas no mousei on existiam mais em função de agradar as divindades do que serem contempladas pelo homem" (Suano, 1986, pp. 10-11).

Internada em 1937, Adelina Gomes, camponesa humilde, cuja tragédia resumia-se no desejo de ser flor, foi acolhida pela doutora $\mathrm{N}$ ise em 1946. Daí em diante, por mais de quatro décadas, pintou e esculpiu todos os dias. 0 desejo de ser deu lugar ao de fazer. Adelina fez flores. Viveu quase toda a sua vida no $\mathrm{M} \mathrm{u}$ seu de I magens do Inconsciente ao lado de $\mathrm{N}$ ise da Silveira, e nele, juntas, permanecem para além do ciclo individual da vida e da morte.

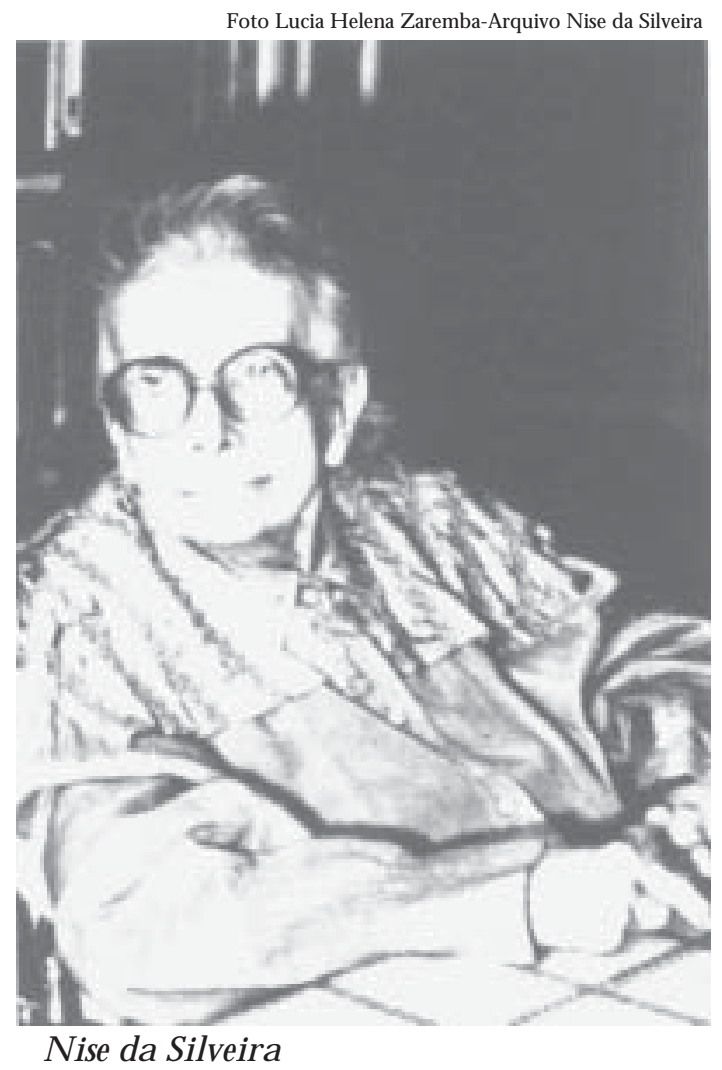

Referências bibliográficas

BEN J AM IN, W. "O narrador". Em Textos escol hidos São Paulo, Abril Cultural, 1983. (Col. "O s Pensadores").

DU BU FFET, J. Prospectuset tous écritssuivants. Paris, Gallimard, 1967, vols. 1 e 2. FOU CAU LT, M. H istoire dela folie à l'âge classique. Paris, Gallimard, 1972.

FRAYZE-PEREIRA, J. Olho d'água. A rte e loucura em exposição. São Paulo, Escuta/ Fapesp, 1995.

FRAYZE-PEREIRA, J. A. "Arte e loucura no museu: uma poética singular". Em FERNADES, M. I. A. (org.). Fim de século: ainda manicômios? São Paulo, I pusp, 1999.

GU LLAR, F. N iseda Silveira: uma psiquiatra rebelde. Rio de J aneiro, R elume-D umará, 1996.

JU N G, C. G. 0 espírito na arte ena ciência. Petrópolis, Vozes, 1985.

MELO, W. N iseda Silveira. Rio de J aneiro, I mago, 2001.

MERLEAU -PONTY, M. L'oeil et l'esprit. Paris, Gallimard, 1964.

PAZ, O. "A identidade cultural dos hispanos". Caderno Cultura - O Estado deS. Paulo, 4-7-1987. 
PEDROSA, M. A rte, forma e personalidade. São Paulo, Kairós, 1979.

. A rte, necessidade vital. Rio de J aneiro, Casa do Estudante do Brasil, 1949.

. Museu de I magens do I nconsciente. Rio de Janeiro, FU NARTE - Instituto N aci-

onal de Artes Plásticas, 1980, pp. 9-11; 119-135 (Col. M useus Brasileiros).

ROZÁRIO , O. CoresAlgemadas. A rtenospresídios. Rio de Janeiro, D ois pontos, 1986.

SILVEIRA, N. "Os inumeráveis estados do ser". Catálogo de Exposição 40 anos de experiência em terapêutica ocupacional. Rio de Janeiro, 1986.

- I magens do inconsciente. Rio de J aneiro, Alhambra, 1981.

. J ung. Rio de Janeiro, Paz e Terra, 1981a.

"A experiência de Engenho de D entro". Catálogo da Exposição A r te I ncomum. 1981b, pp. 36-40.

. "D yonysos - um comentário psicológico". Quaternio, Rio de Janeiro, Grupo de Estudos C. G. Jung, 1973.

STAT O BI N SKI , J. "Préface”. E m Prinzhorn, H . Expressi onsdela folie. Paris, Gallimard, 1984, pp. vii-xvi.

SU AN O, M. O queé museu. São Paulo, Brasiliense, 1986.

THÉVOZ, M. R equien pour la folie Paris, La Différence, 1995. . A rt, folie, graffiti, LSD ... etc. Suisse, Ed. de l'Aire, 1985.

R ESU M O - A HISTÓ RIA de vida de N ise da Silveira é considerada à luz do complexo campo simbólico que sua obra de maior envergadura inaugurou na cultura brasileira - o M useu de I magens do I nconsciente, campo de passagem entre o hospício e o mundo da arte. N este artigo, este museu é anal isado segundo os principais eixos que o articulam: o psicológico, o artístico e o político. É considerado o impacto da art brutt sobre o próprio criador marginal e sobre o olhar do espectador.

A BSTRACT - NISE da Silveira life history is considered under the light of the complex symbolic field, inaugurated by her major work in Brazilian culture - the U nconscious' I mages M useum, a passage field between the asylum and the world of art. I $n$ this paper, this museum is analysed according to the main axis which articulate it: the psychological, the artistic and the political. It's considered the impact of art brutt on the outsider artist and on the espectator's perception.

J oão A. Frayze-Pereira é professor livre-docente do Instituto de Psicologia da U SP e psicanalista do Instituto de Psicanálise da Sociedade Brasileira de Psicanálise de São Paulo. Autor, entre outras publicações, dos seguintes livros: 0 queéloucura. São Paulo, Brasiliense, 1982; A tentação do ambíguo. Sobre a coi sa senśvel e o objetivismo ci entífico. São Paulo, Ática, 1984 (esgotado) e Olho-d'Á gua. A rteeloucura em exposição. São PauIo, Escuta/ Fapesp, 1995.

Texto recebido e aceito para publicação em 16 de setembro de 2003. 